\title{
ACORDOS REGIONAIS DE LIVRE COMÉR- CIO E O MERCADO DE ARROZ NO BRASIL
}

\author{
Augusto M. Alvim \\ Paulo D. Waquil ${ }^{2}$
}

Resumo - Este estudo identifica os efeitos dos novos acordos regionais de livre comércio sobre os produtores de arroz, no Brasil e nas demais regiões relevantes no mercado mundial. Para analisar os efeitos dos acordos comerciais, como, por exemplo, da ALCA, do MERCOSUL-UE e do MERCOSUL-CAN, desenvolve-se um modelo de alocação espacial e temporal utilizando-se um Problema de Complementaridade Mista (PCM). Em termos gerais, os maiores ganhos para os produtores brasileiros de arroz ocorreram com o acordo MERCOSUL-UE, quando a produção brasileira foi estimulada pelo redirecionamento das exportações argentinas e uruguaias para a UE. No entanto, em virtude das dificuldades nas negociações de livre comércio junto à UE, a segunda melhor opção, MERCOSUL-CAN, apresentou-se como alternativa de ganhos intermediários, mas com maior facilidade de implementação.

Palavras-chave: Problema de Complementaridade Mista, arroz e acordos regionais.

${ }^{1}$ Doutor em Economia, professor adjunto do Departamento de Ciências Econômicas, UNISC. Av. Independência, nº 2293, CEP. 96815-900, Santa Cruz do Sul, RS. Fone: 513717 7366. E-mail: alvim@unisc.br.

${ }^{2}$ Ph.D, professor adjunto do Departamento de Ciências Econômicas, UFRGS. Av. João Pessoa, $n^{\circ} 31$, CEP. 90040-000, Porto Alegre, RS. Fone: 513316 3109. E-mail: waquil@ufrgs.br.

Recebido em 15/08/2003 Aceito em 11/09/2003 


\section{Introdução}

A segunda metade do século $\mathrm{XX}$ foi marcada pelas discussões acerca da questão do livre comércio entre países. De maneira geral, as informações existentes sobre este assunto mostram que, quanto mais intenso o comércio de bens e serviços entre países e regiões, maior o crescimento econômico. A razão para isto se deve ao fato de os países concentrarem todos seus esforços nas atividades que são mais eficientes, exportando esses produtos e importando os demais de regiões que os produzem de forma eficiente. Ao maior acesso a mercados (maior número de consumidores e produtores) somam-se os benefícios obtidos, resultando em melhores produtos e preços.

Todavia, não existem apenas ganhos a partir da implementação dos acordos de livre comércio, embora estes sejam observados pela intensificação das atividades, que passam por um processo de reorganização, com vistas na redução dos custos. Por sua vez, esses acordos também determinam mudanças negativas, como, por exemplo, a redução ou até mesmo o desaparecimento de determinadas atividades econômicas em regiões específicas e nos países.

Dessa forma, ainda que haja possibilidade de maiores ganhos globais em bem-estar, observa-se que os países continuam a proteger seus mercados, principalmente os agrícolas, por meio de mecanismos, como barreiras tarifárias e não-tarifárias, e também por meio da concessão de subsídios à produção e à exportação. As justificativas passam por questões das mais diversas, como, por exemplo, de segurança alimentar, de proteção a setores frágeis e de concessão de vantagens a grupos de pressão. Nas últimas décadas, o comércio agrícola entre países cresceu aquém do esperado, visto que o crescimento foi significativamente inferior aos níveis observados na indústria.

O crescimento do comércio agrícola, na última década, deveu-se principalmente aos acordos firmados na Rodada Uruguai ${ }^{3}$ (em nível multilate-

\footnotetext{
${ }^{3}$ Na Rodada Uruguai, que ocorreu entre 1986 e 1994, foram estabelecidas as primeiras medidas que visam reduzir as barreiras comerciais, estabelecidas pelos países-membros, aos produtos agrícolas.
} 
ral) e aos acordos regionais, como, por exemplo, o Acordo de Livre Comércio da América do Norte (NAFTA) e o Mercado Comum do Sul (MERCOSUL). Nesse sentido, o comércio internacional de produtos agrícolas cresceu, em média, $35 \%$, enquanto o de produtos industriais cresceu 94\% no período de 1991 a 2000 (USDA, 2001b). A principal razão para esse fato foi devido às dificuldades enfrentadas nas negociações de livre comércio de produtos agrícolas, em nível multilateral pósRodada Uruguai. Atualmente, os principais obstáculos nas negociações estão na redução das tarifas e das quotas-tarifárias e na elaboração de acordos que, efetivamente, venham a contribuir para a redução dos subsídios e para a padronização das normas fitossanitárias e técnicas entre os países. Apesar de os países desenvolvidos defenderem a redução do protecionismo de forma multilateral, na prática, observa-se justamente o contrário, ou seja, um aumento sistemático dos subsídios e das barreiras não-tarifárias.

Em contraposição a esse cenário, o processo de regionalização vem avançando mais rapidamente do que os acordos multilaterais de livre comércio no mundo. A formação de áreas de livre comércio envolve a reunião de países com características políticas, econômicas, sociais e culturais distintas, todavia, esse processo ocorre com maior dificuldade no caso dos acordos multilaterais, em que as diferenças são ainda mais acentuadas. Outro aspecto relevante para explicar a preferência dos países pelos acordos regionais diante dos multilaterais resulta do elevado número de participantes e da maior abrangência das negociações multilaterais.

Em decorrência das dificuldades enfrentadas em nível multilateral, no mesmo período, houve multiplicação dos acordos de livre comércio, em âmbito regional. Segundo a Organização Mundial de Comércio (OMC), desde 1994, foram reportados 131 acordos de livre comércio entre países que buscam intensificar o comércio (OMC, 2001). Apesar desses acordos regionais, o mercado agrícola mantém níveis elevados de protecionismo. Entre os produtos agrícolas mais protegidos pelos países e blocos econômicos está o arroz, alimento consumido por 1/3 da população mundial e o segundo grão mais utilizado na dieta alimentar (Alvim, 
1998). No mercado de arroz, destacam-se, como principais mecanismos de proteção, as barreiras tarifárias e os subsídios.

Nos últimos anos, devido à intervenção dos principais países exportadores na produção e na comercialização de arroz, mantiveram-se as distorções de mercado, o que fortaleceu a tendência de queda dos preços. Por sua vez, à medida que os preços diminuíam, eram exigidas, por parte dos agricultores, maiores intervenções dos governos na produção e no comércio (subsídios) e maiores barreiras protecionistas (tarifas e quotas-tarifárias). Dessa forma, a demanda de maior suporte governamental pelos agricultores apenas contribuiu para a acelerar a tendência de queda dos preços, à medida que incentivava maior oferta de produto, ocasionando perdas cada vez maiores aos contribuintes e ao governo.

As medidas alternativas a serem adotadas permitiriam criar e, ou, ampliar o acesso a mercados, a fim de incrementar a produção e a comercialização de arroz. Entre essas medidas destacam-se os novos acordos regionais, como, por exemplo, a Área de Livre Comércio das Américas (ALCA), o MERCOSUL-UE ${ }^{4}$ e o MERCOSUL-CAN ${ }^{5}$. Inserido neste cenário tem-se o Brasil, que tem defendido, junto aos fóruns de discussões internacionais, maior intensificação do comércio entre países e regiões por meio da redução das barreiras tarifárias e da eliminação dos subsídios. Entretanto, como a possibilidade de redução das medidas protecionistas vem se tornando cada vez mais difícil, uma parcela dos políticos e pesquisadores brasileiros tem defendido que, primeiramente, devem ser aprofundados os acordos de integração junto ao MERCOSUL.

Uma das estratégias para o fortalecimento do bloco consiste na adoção de políticas comuns setoriais (indústria, agricultura e comércio) e macroeconômicas (fiscal, monetária, cambial), que promovam a transição de uma União Aduaneira para uma Comunidade Econômica. Porém, existem vários empecilhos para o avanço desse processo, dentre os quais, as assimetrias nos países, quanto ao PIB, à área geográfica, à

${ }^{4}$ União Européia (UE).

${ }^{5}$ Comunidade Andina (CAN). 
população e às diferenças econômicas, políticas e sociais, bem como à dificuldade de construir instituições supranacionais.

As negociações de acordos regionais de livre comércio são caminhos alternativos para incrementar o comércio do Brasil com outros países. Entre esses acordos destacam-se a ALCA, o MERCOSUL-UE e o MERCOSUL-CAN. A ALCA, que inclui todos os países das Américas, à exceção de Cuba, e o acordo MERCOSUL-UE objetivam eliminar as barreiras tarifárias existentes entre os países-membros. No entanto, o acordo MERCOSUL-CAN torna possível, além de intensificar o comércio na América do Sul, reunir os países desta região, com vistas em negociar acordos mais vantajosos, em níveis multilateral e regional.

Nas negociações que envolvem a ALCA e a UE, salienta-se, como um dos principais desafios por parte dos países do MERCOSUL, a redução dos subsídios concedidos à produção e à exportação de arroz. Nesse aspecto, enfatiza-se a importância de negociar, simultaneamente, esses acordos regionais com as negociações multilaterais junto à OMC. Essa estratégia permite associar maior redução tarifária, por meio dos acordos regionais, com a redução dos subsídios aos tratados multilaterais.

A partir desse cenário, quer-se avaliar quais seriam os possíveis reflexos dos acordos regionais de livre comércio no setor arrozeiro no Brasil. Considerando-se as condições particulares de cada região, podem ocorrer diferenciais ou vantagens capazes de determinar novo equilíbrio, tendo em vista a criação de novos acordos de integração regional.

Com o propósito de analisar esses novos cenários, é necessário um método apropriado para análise desse mercado e dos efeitos das mudanças, de ordem política, sobre produção, consumo, fluxos comerciais e preços nas principais regiões. Dessa forma, o modelo deve considerar os principais mecanismos de proteção adotados pelos países, como, por exemplo, as tarifas, as quotas-tarifárias e os subsídios.

Dessa forma, foi elaborado um modelo espacial e temporal, na forma de um Problema de Complementaridade Mista. Este modelo permite a in- 
clusão das principais barreiras comerciais aplicadas no mercado de arroz, bem como, a partir da simulação dos novos acordos de livre comércio, a análise dos efeitos da eliminação dos subsídios e da redução das barreiras tarifárias. Enquanto a dimensão espacial possibilita o comércio de arroz entre as regiões, determinando a produção, o consumo e o comércio em cada período, a dimensão temporal, por sua vez, permite a transferência de arroz para o ano seguinte, o que possibilita analisar os efeitos das mudanças políticas ao longo dos anos.

\section{O Problema de Complementaridade Mista: um modelo de alocação espacial e temporal}

O modelo de otimização descrito nesta seção utiliza uma formulação apresentada na forma de um Problema de Complementaridade Mista (PCM), conforme Thore (1992), Rutheford (1995) e Bishop, Nicholson e Pratt (2001). No modelo de equilíbrio espacial e temporal formulado, pressupõe-se que os produtos sejam homogêneos e que a tecnologia e o crescimento populacional sejam variáveis exógenas ao modelo.

A inclusão da dimensão temporal deve-se à importância de avaliar o comportamento dos preços ao longo do tempo, em face das possíveis mudanças de ordem política. Os estoques permitem a transferência de produto de um ano para outro, tornando menos bruscas as alterações nas variáveis analisadas em cada mercado.

Considera-se a alocação de um produto (arroz) em $I$ regiões, em $T$ períodos. Inicialmente, as variáveis utilizadas no modelo são descritas a seguir:

$p_{t, j}^{d}$ : preço do produto na função de demanda Hicksiana para o arroz na região $\mathrm{j}$, no período $\mathrm{t}=1, \ldots, \mathrm{T}$;

$p_{t, i}^{S}:$ preço do produto na função de oferta para o arroz, na região i, no período $\mathrm{t}=1, \ldots, \mathrm{T}$; 
$q_{t, j}^{d}:$ consumo de arroz na região $\mathrm{j}$, no período $\mathrm{t}=1, \ldots, \mathrm{T}$;

$q_{t, i}^{S}$ : produção de arroz na região i, no período $\mathrm{t}=1, \ldots, \mathrm{T}$;

$X_{t, i, w}$ : transferência de arroz da região i para o armazém w, no período $\mathrm{t}=1, \ldots, \mathrm{T}$;

$X_{t, w, j}$ : transferência de arroz do armazém w para a região j, no período $\mathrm{t}=1, \ldots, \mathrm{T}$;

$I_{t+1, w}$ : quantidade estocada no armazém $(\mathrm{w})$, no período $\mathrm{t}=1, \ldots, \mathrm{T}$;

$I n_{w}$ : capacidade máxima de estocagem no armazém (w);

$t_{i, w}$ : custo de transporte da região i para o armazém w;

$t_{w, j}$ : custo de transporte do armazém w para a região j;

$c_{w}:$ custo unitário de armazenagem no armazém w;

$\varphi_{t, i}:$ multiplicador de Lagrange: preço-sombra para o arroz na região produtora $\mathrm{i}$, no período $\mathrm{t}=1, \ldots, \mathrm{T}$;

$\lambda_{t, j}$ : multiplicador de Lagrange: preço-sombra para o arroz na região consumidora $\mathrm{j}$, no período $\mathrm{t}=1, \ldots, \mathrm{T}$;

$\gamma_{t, w}$ : multiplicador de Lagrange: preço-sombra associado ao valor do produto durante a estocagem no armazém $\mathrm{w}$, no período $\mathrm{t}=1, \ldots, \mathrm{T}$;

$\mu_{t, w}$ : multiplicador de Lagrange: preço-sombra associado ao limite na capacidade de estocagem do armazém $w$, no período $t=1, \ldots, \mathrm{T}$.

O Problema de Complementaridade Mista (PCM) consiste em um sistema de equações simultâneas (linear e não-linear), apresentadas na for- 
ma de desigualdades, que estão ligadas a variáveis que delimitam as soluções possíveis. O PCM é equivalente às condições, de Kuhn-Tucker, do problema de maximização da função Net Social Payoff ${ }^{6}$ (NSP). Essas condições são necessárias e suficientes para que haja um máximo da função $\mathrm{NSP}^{7}$, o que, por sua vez, implica equilíbrio em todas as regiões e períodos estudados.

A partir de um conjunto de sistemas de equações, é possível obter o equilíbrio de mercado em todas as regiões $(\mathrm{i}, \mathrm{j})$ e períodos de tempo $(\mathrm{t})$, com base no Problema de Complementaridade Mista apresentado a seguir:

(1.1) $0 \leq \lambda_{t, j} \perp q_{t, j}^{d} \leq \sum_{w}^{W} X_{t, w, j}$;

(1.2) $0 \leq \varphi_{t, i} \perp \sum_{w}^{W} X_{t, i, w} \leq q_{t, i}^{s}$

(1.3) $0 \leq X_{t, i, w} \perp \gamma_{t, w} \leq \varphi_{t, i}+t_{i, w}$;

(1.4) $0 \leq X_{t, w, j} \perp \gamma_{t, w} \geq \lambda_{t, j}-t_{w, j}$;

(1.5) $0 \leq I_{t, w} \perp \gamma_{t+1, w}-\gamma_{t, w} \leq c_{w}+\mu_{t, w} ; \forall t=1, \ldots, T-1$;

\footnotetext{
${ }^{6}$ Samuelson (1952) mostrou que o equilíbrio de mercado pode ser alcançado a partir da maximização da função de Net Social Payoff (NSP), obtida da soma dos excedentes dos produtores e dos consumidores.

${ }^{7}$ Para um problema de programação não-linear, em que a função objetivo é diferenciável e côncava, com restrições lineares (diferenciáveis e convexas), os resultados obtidos serão um máximo global, desde que os pontos ótimos obedeçam às condições de Kuhn-Tucker.
} 
(1.6) $0<\gamma_{t, w} \perp \sum_{j=1}^{J} X_{t, w, j}-\sum_{i=1}^{I} X_{t, i, w}=I_{t-1, w}-I_{t, w}$;

(1.7) $0 \leq \mu_{t, w} \perp I_{t, w} \leq I n_{w} ; \forall t=1, \ldots T-1$.

O símbolo $\perp$ significa que, no mínimo, uma das desigualdades adjacentes devam ser satisfeitas como uma igualdade. Dessa forma, a primeira expressão (1.1) revela que, no momento em que o preço-sombra $\lambda_{t, j}$ for maior que zero, a quantidade consumida $q_{t, j}^{d}$ será igual ao somatório de produtos comprados de "w" armazéns $\sum_{w}^{W} X_{t, w, j}$. Caso contrário, quando o preço-sombra for igual a zero, a quantidade consumida será menor do que o total de produto comercializado (compra) junto aos armazéns ${ }^{8}$. De forma semelhante, a equação (1.2) estabelece que, quando o preço de mercado for maior que zero, o comércio de produto entre a fazenda e os armazéns não poderá superar a produção doméstica na região "i”, em cada período “t”.

As equações 1.3 e 1.4 implicam lucro zero para o setor de transportes. A diferença de preços entre a região de oferta e os armazéns, e entre os armazéns e a região de demanda, deve ser menor ou igual aos custos de transporte. Quando houver comércio entre as regiões, a diferença de preços entre os pontos de oferta e de armazenagem será equivalente ao

\footnotetext{
${ }^{8} \mathrm{Na}$ programação do modelo espacial e temporal como PCM, os coeficientes e as elasticidades são incluídos nas restrições 1.1 e 1.2 , substituindo as quantidades produzidas e consumidas pelas seguintes expressões:
}
a) $q_{t, j}^{d}=c_{j} \cdot \lambda_{t, j}^{d_{j}}$
b) $q_{t, i}^{s}=a_{i} \cdot \varphi_{t, i}^{b_{i}}$. 
custo de transporte.

A mesma regra vale para o comércio entre os pontos de armazenagem e de consumo. A equação 1.5 determina lucro zero na armazenagem do produto. Essa condição estabelece que não pode ocorrer lucro desde o momento em que o produto estiver vindo de um ponto de oferta (i) para o armazém (w) até o momento em que sair do armazém para um certo ponto de demanda (j). Quando houver valorização de uma unidade de produto de um período ao outro $\left(\gamma_{t+1, w}-\gamma_{t, w}\right)$, esta não poderá exceder o custo de estocagem de uma unidade adicional mais o preçosombra relacionado com a capacidade de armazenagem $\left(c_{w}+\mu_{t, w}\right)$. Em outras palavras, a valorização do produto não poderá ser maior do que o custo total de armazenagem, pois, caso contrário, haveria lucro. No caso de o produto ser armazenado, então, $\gamma_{t+1, w}-\gamma_{t, w}=c_{w}+\mu_{t, w}$. Em resumo, se os preços caírem ao longo do tempo, nenhuma quantidade será adicionada ao estoque. Mesmo que os preços cresçam a uma taxa inferior ao montante $\left(c_{w}+\mu_{t, w}\right)$, nenhuma unidade de produto será acrescentada ao armazém, ou seja, valores positivos somente serão acrescentados ao armazém quando o preço crescer a uma taxa igual ao custo total de armazenagem.

Já a equação 1.6 estabelece que a diferença entre a entrada e a saída de produtos dos armazéns deva ser igual à variação nos estoques entre períodos subseqüentes. Dessa forma, haverá um limite para a formação dos estoques, dado pela capacidade de armazenagem em cada região, isto é, nenhuma região poderá armazenar acima da sua capacidade, em cada período " $\mathrm{t}$ ".

Essas condições permitem obter os preços de mercado, as quantidades consumidas, produzidas e armazenadas, bem como o fluxo comercial entre as regiões analisadas, em cada período de tempo (t). Elas são apresentadas na forma de PCM, para possibilitar a inclusão das tarifas e 
quotas-tarifárias. A seguir, são discutidas as modificações necessárias para incluir tarifas ad valorem e as quotas-tarifárias ao modelo espacial e temporal, desenvolvido a partir da abordagem PCM.

\subsection{A inclusão de tarifas ad valorem e quotas-tarifárias no PCM}

Conforme discutido anteriormente, como os preços-sombra são apresentados de maneira explícita, podem-se incluir diretamente nos preços variáveis como tarifas, quotas-tarifárias e subsídios. Nagurney, Nicholson e Bishop (1996) sugeriram a inclusão das tarifas ad valorem nos modelos de equilíbrio espacial primal, para que os resultados fossem representativos de uma realidade em que o principal instrumento de política comercial eram as barreiras comerciais impostas pelas tarifas.

As modificações sugeridas pelos autores partiram do modelo espacial básico desenvolvido por Takayama e Judge (1971), no qual se pressupôs um mercado de competição perfeita sem a intervenção dos governos na economia. Nesse caso, foram definidos alguns pressupostos básicos do modelo, conforme apresentado a seguir. Para um conjunto de produtores e consumidores $(i, j) ; i=1, \ldots, I ; j=1, \ldots, J$, a oferta, a demanda e a quantidade transportada $\left(q_{i}^{s}, q_{j}^{d}\right.$ e $\left.X_{i, j}\right)$, respectivamente, de um produto agrícola devem satisfazer às seguintes possibilidades:

(1.8) $t_{i, j}+\varphi_{i}=\lambda_{j}$, se $\mathrm{X}_{\mathrm{i}, \mathrm{j}}>0$

(1.9) $t_{i, j}+\varphi_{i} \geq \lambda_{j}$, se $\mathrm{X}_{\mathrm{i}, \mathrm{j}}=0$.

Em outras palavras, no equilíbrio, se existir um fluxo comercial entre as regiões i e j, então o preço do produtor na região i mais o custo de transporte $(i, j)$ deverão ser iguais ao preço do consumidor na região j, caso contrário, se o preço no mercado produtor mais os custos de transporte forem maiores do que o preço do consumidor, não haverá comércio entre as duas regiões. 
Para introduzir as tarifas e quotas-tarifárias no modelo descrito, Nagurney, Nicholson e Bishop (1996) e Bishop, Nicholson e Pratt (2001) sugeriram as seguintes modificações nas condições de equilíbrio. Para incluir tarifas e o sistema de quotas, parte-se das equações 1.8 e 1.9 apresentadas anteriormente. As equações que incluem a tarifa $\left(\operatorname{tar}_{i, j}\right)$ e as quotastarifárias $\left(\mathrm{Q}_{\mathrm{t}, \mathrm{i}, \mathrm{w}}, \mathrm{Q}_{\mathrm{t}, \mathrm{w}, \mathrm{j}}\right)$, em um modelo espacial e temporal, são reapresentadas da seguinte forma, dado que $\mathrm{qr}_{\mathrm{t}, \mathrm{i}, \mathrm{w}}$ e $\mathrm{qr} \mathrm{t}_{\mathrm{t}, \mathrm{w}, \mathrm{j}}$ são taxas adicionais acrescidas às tarifas:

(1.10) $\left(t_{i, w}+\varphi_{t, i}\right) \cdot\left(1+\operatorname{tar}_{t, i, w}+q r_{t, i, w}\right)=\gamma_{t, w}$, se $X_{t, i, w}>0$;

(1.11) $\left(t_{i, w}+\varphi_{t, i}\right) \cdot\left(1+\operatorname{tar}_{t, i, w}+q r_{t, i, w}\right) \geq \gamma_{t, w}$, se $\mathrm{X}_{\mathrm{t}, \mathrm{i}, \mathrm{w}}=0$;

(1.12) $\left(\gamma_{t, w}+t_{w, j}\right) .\left(1+\operatorname{tar}_{t, w, j}+q r_{t, w, j}\right)=\lambda_{t, j}$, se $\mathrm{X}_{\mathrm{t}, \mathrm{w}, \mathrm{j}}>0$;

(1.13) $\left(\gamma_{t, w}+t_{w, j}\right) \cdot\left(1+\operatorname{tar}_{t, w, j}+q r_{t, w, j}\right) \geq \lambda_{t, j}$, se $\mathrm{X}_{\mathrm{t}, \mathrm{w}, \mathrm{j}}=0$.

Sendo incluídas as seguintes novas condições:

$$
Q_{t, i, w}=X_{t, i, w}, \text { se } \mathrm{qr}_{\mathrm{t}, \mathrm{i}, \mathrm{w}}>0
$$

(1.15) $Q_{t, i, w}>X_{t, i, w}$, se $\mathrm{qr}_{\mathrm{t}, \mathrm{i}, \mathrm{w}}=0$;

(1.16) $Q_{t, w, j}=X_{t, w, j}$, se qr $\mathrm{t}, \mathrm{w}, \mathrm{j}>0$;

(1.17) $Q_{t, w, j}>X_{t, w, j}$, se qr $\mathrm{t}_{\mathrm{t}, \mathrm{w}, \mathrm{j}}=0$,

ou, simplesmente, 
(1.18) $0 \leq X_{t, i, w} \perp \gamma_{t, w} \leq\left(t_{i, w}+\varphi_{t, i}\right) \cdot\left(1+\operatorname{tar}_{t, i, w}+q r_{t, i, w}\right)$;

(1.19) $0 \leq X_{t, w, j} \perp \lambda_{t, j} \leq\left(\gamma_{t, w}+t_{w, j}\right) .\left(1+t a r_{t, w, j}+q r_{t, w, j}\right)$;

(1.20) $0 \leq q r_{t, i, w} \perp Q_{t, i, w} \geq X_{t, i, w}$;

(1.21) $0 \leq q r_{t, w, j} \perp Q_{t, w, j} \geq X_{t, w, j}$.

As equações 1.18 e 1.19 determinam que, no caso de os fluxos comerciais entre determinada região $\mathrm{i}$, para a região $\mathrm{w}$, serem maiores do que zero, porém inferiores à quota estabelecida pela região $\mathrm{w}\left(\mathrm{Qt}_{\mathrm{i}, \mathrm{w}, \mathrm{t}}\right)$, o preço do produto na região $\mathrm{w}$, no período $\mathrm{t}$, dependerá apenas do preço na região i, dos custos de transporte da região i para w e da tarifa imposta ao produto originário da região i. Por outro lado, no caso de as importações da região w serem iguais à quota determinada para a região, então o preço do produto na região $\mathrm{w}$, no período t, dependerá não apenas do preço, dos custos de transportes e das tarifas, mas também de uma taxa $\mathrm{qr}_{\mathrm{i}, \mathrm{w}, \mathrm{t}}$. A variável $\mathrm{qr}_{\mathrm{i}, \mathrm{w}, \mathrm{t}}$ equivale a uma taxa percentual determinada endogenamente no modelo, com o objetivo de proibir importações ao mercado w acima da quota estabelecida. Dessa forma, independente do nível dos preços internacionais, quando a quota for utilizada, cessarão os fluxos comerciais entre as regiões. Similarmente, as equações 1.20 e 1.21 estabelecem o mesmo mecanismo que simula o efeito das quotastarifárias, embora, nesse caso, as regiões de origem do produto sejam as regiões w, e as regiões de destino do produto, as regiões j.

A inclusão do sistema de quotas-tarifárias no modelo deve-se, basicamente, à EU, que utiliza esse sistema de barreiras para garantir maiores preços ao arroz produzido no bloco. A partir disto, no modelo incluem-se novas condições relacionadas com as quotas-tarifárias, que permitem a importação de arroz a partir da imposição de tarifas preferenciais em apenas um nível, ou seja, a partir do momento em que as importações de 
arroz pela UE forem iguais à quota, serão proibidas importações adicionais no período considerado.

\subsection{As informações utilizadas no modelo}

Os preços de arroz e as quantidades consumidas e ofertadas foram obtidos do banco de dados da FAO, utilizando-se a média dos anos de 1998-2000. No modelo, conforme apresentado anteriormente, utilizaramse as elasticidades-preço de oferta e de demanda, obtidas do trabalho de Sullivan et al. (1992). Os custos totais de transporte foram obtidos do USDA (2002) e do Banco Mundial (2002). Já as tarifas ad valorem sobre as importações foram obtidas do banco de dados da UNCTAD (2001). As informações sobre a capacidade de armazenagem e sobre os custos de armazenagens, nos países e regiões analisadas, foram estimadas a partir dos informes da CONAB e do USDA. Quanto à capacidade máxima de armazenagem, esta foi estimada pelos informes dos estoques de passagem de arroz, obtidos de USDA (2001b), considerando-se uma média do período de 1998-00. Já os subsídios americanos foram obtidos de informes do USDA (2001a).

\section{Resultados}

A área de estudo abrange o mercado mundial de arroz, que inclui os principais países produtores, importadores e exportadores. Para melhor análise da produção, consumo e comércio de arroz no mundo, estes países foram agrupados em blocos econômicos e, ou, regiões participantes desse mercado. O critério para escolha das regiões e países se deu com base na importância da produção, do consumo e do comércio, como também levou em consideração as regiões que possuíam maior afinidade comercial com o Brasil. 
Quanto aos países pertencentes à $\mathrm{ASEAN}^{9}$, à $\mathrm{CAN}^{10}$, ao MERCOSUL ${ }^{11}$, ao NAFTA ${ }^{12}$, ao SAPTA $^{13}$ e à UE ${ }^{14}$, estes foram agrupados por apresentarem maior afinidade comercial entre si e, ou, por terem políticas comerciais comuns. Os países de pequena relevância, em produção, consumo e comércio de arroz, foram agrupados pelos critérios de afinidade geográfica e econômica, embora não possuíssem acordos de livre comércio. Nessa categoria estão Outros Países da América do Sul $(\mathrm{OAS})^{15}$, Outros Países da Ásia e Oceania (OPA e Oceania $)^{16}$ e Países da África, da Europa Oriental e da América Central. A China não foi incluída em nenhum grupo de países, dada a sua importância como produtora, consumidora e exportadora de arroz. A última região foi chamada de "resto do mundo" e incluía todos os países que não pertenciam às regiões e blocos comerciais apresentados.

\subsection{Apresentação do cenário-base}

A Tabela 1, apresentada a seguir, mostra as principais diferenças entre produção, consumo e preços observados, cujos resultados foram estimados pelo modelo. Conforme já discutido, os resultados da produção e do consumo foram obtidos do banco de dados da FAO (média 1998-2000). Os preços de arroz foram calculados a partir das quantidades e dos valores das exportações e importações realizadas pelos países e pelas regiões em estudo. No caso específico do Canadá e do Paraguai, utilizaram-se os preços do NAFTA e do MERCOSUL, respectivamente.

\footnotetext{
${ }^{9}$ A Associação das Nações do Sudeste Asiático (ASEAN) tem, como países-membros, a Indonésia, a Malásia, as Filipinas, a Tailândia, Cingapura, o Vietnã, Laos, o Camboja, a Mianmar e o Brunei.

${ }^{10}$ A Comunidade Andina (CAN) é constituída por Bolívia, Colômbia, Equador, Peru e Venezuela.

${ }^{11}$ O Mercado Comum do Sul (MERCOSUL) tem, como membros, o Brasil, a Argentina, o Uruguai e o Paraguai.

${ }^{12} \mathrm{O}$ Acordo de Livre Comércio da América do Norte (NAFTA) é formado pelos Estados Unidos da América (EUA), Canadá e México.

${ }^{13}$ O Acordo Preferencial de Comércio do Sul da Ásia (SAPTA) prevê uma cooperação regional entre Índia, Bangladesh, Butan, Maldivas, Nepal, Paquistão e Srilanka.

${ }^{14}$ A União Européia (UE) reúne os seguintes países: Alemanha, Áustria, Bélgica, Dinamarca, Espanha, Finlândia, França, Grécia, Holanda, Irlanda, Itália, Luxemburgo, Portugal, Reino Unido e Suécia.

${ }^{15}$ A OAS inclui os países da América do Sul que não participam do MERCOSUL e da CAN.

${ }^{16}$ A OPA inclui todos os países asiáticos que não pertencem a ASEAN e SAPTA, bem como exclui a China. A região "OPA e Oceania" considera, além dos países asiáticos descritos acima, os países da Oceania.
} 
Tabela 1- Produção, consumo e preços observados e estimados de arroz, em equivalente beneficiado (média 1998-2000) - mil ton, $\mathrm{US} \$ / \mathrm{kg}$

\begin{tabular}{|c|c|c|c|c|c|c|c|c|c|}
\hline \multirow[b]{2}{*}{ Países } & \multicolumn{3}{|l|}{ Observados } & \multicolumn{3}{|l|}{ Estimados } & \multicolumn{3}{|l|}{\begin{tabular}{|l|} 
Variaçōes \\
\end{tabular}} \\
\hline & $\begin{array}{l}\text { Produçào } \\
\text { múl toneladas }\end{array}$ & Consumo & $\begin{array}{l}\text { Preq̧as } \\
\text { US\$ } / \mathrm{kg}_{\varepsilon}\end{array}$ & $\begin{array}{l}\text { Praduçăo } \\
1^{\mathbb{D}} \text { and }\end{array}$ & $\begin{array}{l}\text { Consumo } \\
1^{\text {th } \text { ano }}\end{array}$ & $\begin{array}{l}\text { Preças } \\
\text { US } \$ / \mathrm{kg}\end{array}$ & $\begin{array}{l}\text { Produçầ } \\
\%\end{array}$ & $\begin{array}{l}\text { Consumo } \\
\%\end{array}$ & $\begin{array}{l}\text { presco } \\
\%\end{array}$ \\
\hline Argentina & 797,919 & 255,097 & 0,300 & 811,717 & 252,920 & 0,306 & 1,73 & $-0,85$ & 2,00 \\
\hline Brasil & $6 \$ 31,452$ & 7787,590 & 0,331 & 6787,471 & 7844,291 & 0,326 & $-0,64$ & 0,73 & $-1,51$ \\
\hline Paraguai & 61,187 & 58,515 & 0,305 & 62,143 & 57,958 & 0,314 & 1,56 & $-1,12$ & 2,98 \\
\hline Uruguaj & 772,489 & 73,417 & 0,310 & 768,545 & 73,691 & 0,307 & $-0,51$ & 0,37 & $-0,97$ \\
\hline CAN & 4104,661 & 4348,525 & 0,398 & 4024,177 & 4367,846 & 0,387 & $-1,96$ & 0,44 & $-2,84$ \\
\hline DAS & 573,858 & 351,008 & 0,364 & 559,287 & 357,635 & 0,347 & $-2,54$ & 1,89 & $-4,62$ \\
\hline Canadi & 0,000 & 259,576 & 0,359 & 0,000 & 263,266 & 0,339 & 0,00 & 1,42 & $-5,60$ \\
\hline EUA & 5889,034 & 3362,208 & 0,349 & 5698,269 & 3432,122 & 0,322 & $-3,24$ & 2,08 & $-7,84$ \\
\hline Méxjco & 268,892 & 637,691 & 0,345 & 269,757 & 636,431 & 0,347 & 0,32 & -0.20 & 0,64 \\
\hline Am. Central & 845,005 & 1472,331 & 0,366 & 886,519 & 1469,513 & 0,367 & 0,17 & -0.19 & 0,38 \\
\hline $\mathrm{UE}$ & 1716,932 & 2220,047 & 0,577 & 1697,233 & 2256,949 & 0,558 & $-1,15$ & 1,66 & $-3,21$ \\
\hline Eur. Oriental & 29,283 & 406,473 & 0,349 & 29,501 & 404,972 & 0,357 & 0.74 & -0.37 & 2,38 \\
\hline Ching & 131942,860 & 128937,015 & 0,267 & 131419,098 & 129347,947 & 0,268 & $-0,40$ & 0,32 & 0,49 \\
\hline ASEAN & 96672,803 & 91135,152 & 0,278 & 95793,807 & 91387,754 & 0,271 & $-0,91$ & 0,28 & $-2,55$ \\
\hline SAPTA & 119787,844 & 116286,103 & 0,298 & 119826,546 & 116239,157 & $a, 299$ & 0,013 & -0.04 & 0,23 \\
\hline OPA e Octania & 17227,145 & 22340,811 & 0,385 & 17218,333 & 22355,104 & 0.384 & $-0,05$ & 0,06 & $-0,13$ \\
\hline Africa & 11411,695 & 16037,867 & 0,325 & 11627,344 & 15767,229 & 0,343 & 1,89 & $-1,69$ & 5,70 \\
\hline R. Mundo & 757,925 & 1762,485 & 0,317 & 765,586 & 1730,548 & 0,332 & 1,01 & $-1,81$ & 4,83 \\
\hline
\end{tabular}

Fonte: Resultados de pesquisa; FAO, 2002.

Embora na Tabela 1 seja apresentado apenas um período, o cenáriobase inclui cinco períodos, considerando-se os estoques iniciais e finais iguais a zero. Dessa maneira, os resultados obtidos da produção, do consumo, dos preços e do fluxo comercial foram iguais em todos os períodos ${ }^{17}$. Basicamente, não foram utilizados mais de cinco períodos na análise, porque, em todos os cenários (base e alternativos), os resultados convergiram em, no máximo, dois períodos, depois de incluída a última mudança.

Outro aspecto a ser salientado no cenário-base é a questão da ajuda humanitária ofertada pelos EUA à África. Conforme informações disponíveis no USDA (2001a), cerca de $25 \%$ das exportações americanas

\footnotetext{
${ }^{17}$ Isto ocorre somente no cenário-base, onde as condições (restrições) do modelo são mantidas constantes em todos os períodos. A ausência de mudanças entre os períodos no cenário-base deve-se ao fato de o modelo considerar a tecnologia e a taxa de crescimento populacional constantes, bem como pelo fato de o modelo não incluir incertezas e choques.
} 
se deu na forma de ajuda humanitária. Com vistas em considerar, pelo menos em parte, esse aspecto, foi incluído um desconto no valor das exportações americanas, em direção à África, de cerca de $15 \%$, definido na calibragem do modelo, com o objetivo de aproximar os preços de arroz dos EUA e da África aos preços observados.

Nesse sentido, as principais regiões produtoras foram China, ASEAN e SAPTA, e os principais consumidores de arroz se encontraram na região da Ásia. Os países do MERCOSUL foram exportadores líquidos, embora o Brasil importasse arroz dos demais países do bloco. A região do NAFTA foi a maior exportadora líquida de arroz, devido aos excedentes gerados pela produção americana. Por outro lado, embora os países da CAN e da UE tenham tido menor consumo do que as demais regiões, foram importadores líquidos de arroz.

Quanto aos preços de arroz em equivalente beneficiado, salientam-se três grupos: no primeiro deles, os preços foram mais elevados, no qual estavam incluídos os países do NAFTA, os demais países das Américas (à exceção dos países do MERCOSUL) e a UE. Os países do MERCOSUL constituíam um grupo de países onde os preços eram intermediários. Por último, estavam os países da Ásia, como, por exemplo, os da ASEAN e do SAPTA, e a China, cujos preços eram menores.

Os resultados apresentados na Tabela 1 mostram as diferenças, na produção, no consumo e nos preços, entre os valores observados e os obtidos da simulação. As maiores diferenças na produção, no cenário estimado e no observado, ocorreram nos EUA e nos OAS, com diferenças de $3,2 \%$ e $2,5 \%$. As diferenças no consumo observado e estimado foram ainda menores; a maior variação ocorreu nos EUA, com uma diferença de $2,1 \%$. As diferenças nos preços foram maiores do que nas demais variáveis, com destaque para os EUA, OAS e África, cujas diferenças entre os preços observados e estimados foram equivalentes a $7,8 \%, 5,6 \%$ e $5,7 \%$, respectivamente.

Outro aspecto importante a ser observado são os fluxos comerciais entre as regiões analisadas. Os países do MERCOSUL concentraram suas 
trocas entre os países-membros, tendo o Brasil como importador e os demais países como exportadores de arroz ao mercado brasileiro. Por sua vez, as exportações de arroz americano tiveram um destino diversificado, principalmente para os demais países do NAFTA, da América Central, da África e da UE. Os países da Ásia e Oceania concentraram o comércio de arroz naquela região, onde países/regiões como China, ASEAN e SAPTA eram os principais exportadores, e a região "OPA e Oceania", região importadora líquida de arroz.

Por fim, quando analisadas as variáveis como produção, consumo e preços, conclui-se que a diferença entre os resultados observados e estimados foi pequena. $\mathrm{O}$ modelo pode ser validado no cenário-base, pois os resultados observados no mundo real foram condizentes com os estimados pelo modelo. Na próxima seção são apresentados e analisados os diversos cenários alternativos e avaliadas as variações, em relação ao cenário-base, na produção, no consumo, no fluxo comercial, nos preços e nos excedentes do produtor e do consumidor.

\subsection{Comportamento da produção, dos preços, das importações e do excedente do produtor no Brasil, nos diversos cenários}

Nesta seção é analisado o impacto dos diversos cenários na produção, nos preços, nas importações e nos excedentes do produtor, no Brasil. Para isto, são estudados os efeitos dos acordos comerciais no período de cinco anos, considerando-se os cronogramas de descontos tarifários e a eliminação dos subsídios, apresentados anteriormente.

A Tabela 2 apresenta uma síntese dos principais resultados obtidos do Brasil e mostra os efeitos dos possíveis novos acordos comerciais sobre o mercado de arroz, em todos os períodos analisados. Observa-se que, em todos os cenários, à exceção do cenário 2a, na medida em que foram reduzidas as barreiras tarifárias e retirados os subsídios, ocorreram sucessivos aumentos na produção. Dessa forma, verifica-se que, independente do grau de abertura comercial (desconto tarifário) negociado em cada cenário, havia efeitos positivos sobre a produção de arroz no Brasil. 
Tabela 2- Produção, preços, importações e excedentes do produtor no Brasil, nos diversos cenários e períodos analisados

\begin{tabular}{|c|c|c|c|c|c|c|c|c|c|}
\hline Produção (mil t) & período & Cenário 1 & $\%$ & Cenário 2a & $\%$ & Cenário $2 b$ & $\%$ & Cenário 3 & $\%$ \\
\hline & 1 & 6787,471 & & 6787,471 & & 6787,471 & & 6787,471 & \\
\hline & 2 & 6788,453 & 0,0 & 6812,032 & 0,4 & 6835,422 & 0,7 & 6850,296 & 0,9 \\
\hline & 3 & 6827,132 & 0,6 & 6818,834 & 0,5 & 6891,627 & 1,5 & 6937,110 & 2,2 \\
\hline & 4 & 6872,239 & 1,2 & 6806,874 & 0,3 & 6914,478 & 1,9 & 7022,324 & 3,5 \\
\hline & 5 & 6872,239 & 1,2 & 6806,874 & 0,3 & 6914,478 & 1,9 & 7078,975 & 4,3 \\
\hline \multicolumn{10}{|l|}{ Preços (dólar) } \\
\hline & 1 & 0,326 & & 0,326 & & 0,326 & & 0,326 & \\
\hline & 2 & 0,326 & 0,0 & 0,329 & 0,9 & 0,331 & 1,5 & 0,333 & 2,1 \\
\hline & 3 & 0,330 & 1,2 & 0,329 & 0,9 & 0,338 & 3,7 & 0,344 & 5,5 \\
\hline & 4 & 0,336 & 3,1 & 0,328 & 0,6 & 0,341 & 4,6 & 0,355 & 8,9 \\
\hline & 5 & 0,336 & 3,1 & 0,328 & 0,6 & 0,341 & 4,6 & 0,362 & 11,0 \\
\hline \multicolumn{10}{|l|}{ Importação (mil t) } \\
\hline & 1 & 1056,821 & & 1056,821 & & 1056,821 & & 1056,821 & \\
\hline & 2 & 1054,562 & $-0,2$ & 1000,448 & $-5,3$ & 946,990 & $-10,4$ & 913,109 & $-13,6$ \\
\hline & 3 & 965,911 & $-8,6$ & 984,880 & $-6,8$ & 819,418 & $-22,5$ & 717,081 & $-32,1$ \\
\hline & 4 & 863,284 & $-18,3$ & 1012,267 & $-4,2$ & 767,904 & $-27,3$ & 527,454 & $-50,1$ \\
\hline & 5 & 863,284 & $-18,3$ & 1012,267 & $-4,2$ & 767,904 & $-27,3$ & 402,867 & $-61,9$ \\
\hline \multicolumn{10}{|c|}{ EP (milhões de dólares) } \\
\hline & 1 & 2790,323 & & 2790,323 & & 2790,323 & & 2790,323 & \\
\hline & 2 & 2791,127 & 0,0 & 2810,483 & 0,7 & 2829,800 & 1,4 & 2842,144 & 1,9 \\
\hline & 3 & 2822,941 & 1,2 & 2816,088 & 0,9 & 2876,693 & 3,1 & 2915,138 & 4,5 \\
\hline & 4 & 2860,441 & 2,5 & 2806,239 & 0,6 & 2895,952 & 3,8 & 2988,376 & 7,1 \\
\hline & 5 & 2860,441 & 2,5 & 2806,239 & 0,6 & 2895,952 & 3,8 & 3037,950 & 8,9 \\
\hline
\end{tabular}

Fonte: Resultados de pesquisa.

De maneira geral, os maiores ganhos foram obtidos no cenário 3, no qual se pressupõe a formação de uma área de livre comércio entre o MERCOSUL e a UE. A produção brasileira foi estimulada, basicamente, pelo redirecionamento das exportações argentinas e uruguaias aos países da UE. Nesse panorama, a produção de arroz brasileira passou de 6787,5 mil toneladas, no cenário-base, para 7079 mil toneladas. Por outro lado, os preços de arroz nos países do MERCOSUL aumentaram, tendo em vista que foram mantidas as barreiras tarifárias, em ambos os blocos, nos terceiros países. A exemplo disto, o preço do arroz brasileiro aumentou $11,0 \%$, e as importações brasileiras reduziram $61,9 \%$. Com 
isto, os excedentes dos produtores, no Brasil, aumentaram 8,9\%, devido às variações positivas em preços e quantidades. No entanto, a maior dificuldade desse cenário foi negociar a eliminação das quotas-tarifárias por parte da UE, o que determinaria perdas importantes para seus produtores.

Em uma posição intermediária estão os cenários 1 e 2b, que apresentaram desempenhos muito próximos em relação aos impactos na produção. Embora o cenário $2 \mathrm{~b}$ tenha apresentado sutil vantagem, em termos de produção, sobre o cenário 1 , o maior problema do cenário 2 b era relativo à dificuldade de negociar a eliminação (redução) dos subsídios americanos, em nível regional. Dessa forma, o cenário 1 possibilitou ótima resposta de produção associada à maior facilidade na implementação desse acordo. Nessas circunstâncias, a produção brasileira passou de 6787,5 mil toneladas, no cenário-base, para 6872,2 mil toneladas. Quanto aos efeitos sobre o consumo, houve perdas nesses cenários, contudo, elas também foram consideradas intermediárias quando comparadas com as dos demais cenários, pois os preços não tiveram aumento muito acentuado como no cenário 3. Neste cenário, os preços aumentaram $3,1 \%$ e as importações brasileiras reduziram $18,3 \%$. Com o aumento dos preços e da quantidade produzida, o excedente dos produtores aumentou $8,9 \%$, neste cenário.

Os piores cenários para os produtores de arroz, no Brasil, foram os cenários 2a. Ambos admitiram a eliminação (redução) das barreiras tarifárias sem considerar nas negociações a eliminação dos subsídios americanos concedidos à produção. Isto sugere que em todas as negociações de acordos comerciais, cujos parceiros eram os EUA, tenha sido negociada, juntamente com a eliminação das barreiras tarifárias, a eliminação (redução) dos subsídios. Por outro lado, neste cenário os consumidores praticamente não tiveram seu consumo alterado, dado que os preços nesses cenários permaneceram praticamente estáveis.

Contudo, é pouco provável que, após a implementação dos novos acordos de livre comércio, possa ocorrer queda no consumo tão acentuada 
quanto a observada a partir da simulação dos cenários alternativos. Nesse sentido, as perdas dos consumidores podem ser menores, na medida em que, simultaneamente aos acordos de livre comércio, existem crescimento populacional, mudanças na renda e diferenciação de produtos, aspectos mantidos constantes na análise.

Como resultado, o bem-estar total pode ser estimado quando se somam as variações nos excedentes dos produtores com a dos consumidores. Em todos os cenários ocorreram perdas em bem-estar total para o Brasil, pois as perdas dos consumidores foram levemente maiores do que os ganhos dos produtores. As perdas líquidas, em termos de excedentes totais, foram mais acentuadas nos cenários 3, 2b e 1, cujos prejuízos foram de 12,8, 9,9 e 21,7 milhões de dólares, respectivamente.

O fato de a produção de arroz, no Brasil, ter respondido positivamente em todos os cenários revela elevada competitividade por parte dos produtores de arroz, já que até mesmo nos piores cenários houve reduzidos ganhos para os produtores. Contudo, a partir desses resultados, fica reforçada a importância das negociações de livre comércio, particularmente as que envolvem os EUA, quando permitem a redução ou a eliminação dos subsídios, pois são nesses cenários que os produtores de arroz no Brasil obtêm os maiores ganhos.

Outro aspecto relevante, quando se busca obter maiores vantagens nas negociações de acordos comerciais que envolvem o arroz, está relacionado com as exportações dos demais parceiros do MERCOSUL. Os melhores cenários para os produtores brasileiros são aqueles que possibilitam maiores exportações por parte da Argentina e do Uruguai, a exemplo dos acordos MERCOSUL-UE e MERCOSUL-CAN. Esses resultados reforçam a importância de uma ação conjunta dos países do MERCOSUL para criar uma política comum setorial que busque organizar, promover e incentivar as exportações do bloco para terceiros países, conforme discutido no final do capítulo três.

Quando se consideram os efeitos totais líquidos em termos de bem-estar, tem-se, como resultado, que os efeitos líquidos totais (avaliados a partir 
dos excedentes totais) ficaram muito próximos de zero, embora negativos. Nesse sentido, deve ser enfatizado que as perdas dos consumidores observadas em todos os cenários, quando divididas por cada brasileiro, foram muito pequenas. Por outro lado, os ganhos que os produtores obtiveram em cada cenário ficaram concentrados em um pequeno grupo da sociedade, sendo capazes de promover o fortalecimento e o desenvolvimento de um setor produtivo importante para a economia brasileira.

\section{Considerações finais}

Em termos gerais, os maiores ganhos para os produtores brasileiros de arroz foram obtidos pelo acordo MERCOSUL-UE, quando a produção brasileira foi estimulada pelo redirecionamento das exportações argentinas e uruguaias para a UE. Nesse cenário, os maiores benefícios foram garantidos porque foram mantidas as barreiras tarifárias aos terceiros países, enquanto os consumidores dos países do MERCOSUL e os produtores da UE apresentaram as maiores perdas.

Os acordos comerciais, como o MERCOSUL-CAN e a ALCA (com eliminação dos subsídios), possibilitaram ganhos intermediários aos produtores brasileiros. Todavia, ainda que a ALCA permitisse maiores benefícios do que o MERCOSUL-CAN, o maior problema do primeiro era a dificuldade de eliminar os subsídios e reduzir as barreiras tarifárias, enquanto o MERCOSUL-CAN garantia ganhos associados à maior facilidade na implementação do acordo.

Todos os cenários analisados resultaram em perdas de bem-estar agregado no Brasil, na medida em que as perdas dos consumidores foram maiores do que os ganhos dos produtores. Os casos onde são observadas maiores perdas líquidas são o MERCOSUL-CAN, a ALCA (com eliminação dos subsídios) e o MERCOSUL-UE com prejuízos de 9,9, 13,7 e 21,7 milhões de dólares, respectivamente.

Conforme resultados apresentados, em todos os cenários foram obtidos 
ganhos para os produtores de arroz no Brasil. Dessa forma, a melhor estratégia para o setor arrozeiro brasileiro seria firmar, junto ao governo brasileiro, uma posição a favor do livre comércio regional. Todavia, a estratégia desse setor poderia concentrar-se em dois pontos de atuação: no primeiro, pela demanda de acordos regionais, como MERCOSULCAN, que possui como vantagem os ganhos em bem-estar para os produtores e o fortalecimento dos elos regionais; no segundo, pelo apoio à negociação conjunta do acordo de livre comércio multilateral com a ALCA e com o MERCOSUL-UE, com vistas em viabilizar maior redução das barreiras tarifárias e dos subsídios.

Esses resultados e recomendações para o setor arrozeiro brasileiro definem posições praticamente opostas às defendidas pelas entidades representativas dos produtores de arroz. Principalmente nos últimos anos, o setor tem defendido posições claramente protecionistas junto ao governo federal, demandando mecanismos como, por exemplo, aumento da TEC e enquadramento do setor na lista de exceções e de medidas temporárias, como a criação de quotas de importação e medidas fitossanitárias para produtos oriundos da Argentina e do Uruguai.

Esses mecanismos são exigidos pelas entidades representativas do setor arrozeiro brasileiro, em razão dos crescentes excedentes do MERCOSUL, os quais se traduzem em menores preços de arroz nesse mercado, já que não há tradição de exportar este produto a terceiros países. Contudo, a expectativa é de que a produção de arroz nesses países mantenha o crescimento ao longo dos próximos anos. Dado esse quadro e dadas as políticas sugeridas, é necessário ampliar o mercado de arroz produzido no MERCOSUL, mediante a organização da produção em termos regionais e a busca de novos acordos de livre comércio, visando não apenas ao consumo doméstico (principalmente no Brasil), mas também à exportação de arroz.

A contribuição empírica deste trabalho está na análise e na recomendação das políticas comerciais mais apropriadas para o setor arrozeiro brasileiro diante do mercado internacional. Nesse sentido, são indicados os 
melhores cenários e as vantagens e desvantagens de cada posição. Já a contribuição metodológica permite obter os resultados mais próximos da realidade, a partir da elaboração de um modelo espacial e temporal que analisa a formação de preços em cada região nos diversos períodos considerados. O ponto fundamental desta metodologia está no uso da formulação matemática na forma de PCM, a fim de incluir as principais barreiras tarifárias existentes no mercado de arroz nos diversos países analisados.

\section{Referências bibliográficas}

\section{ALVIM, A. M. Competitividade do Arroz Gaúcho Frente ao Mer- cado Internacional. Porto Alegre: IEPE/UFRGS, 1998. (Dissertação} de Mestrado n. 199).

BANCO MUNDIAL. Ileana Cristina Neagu (ineagu@worldbank.org). cópia 24 set. 2002. E-mail para Augusto Mussi Alvim (augusto.alvim@ig.com.br).

BISHOP, P.M., NICHOLSON, C.F., e PRATT, J.E. Tariff-Rate Quotas: difficult to model or plain simple. Wellington: NZIER, 2001 (Paper presented at the annual conference of the New Zealand Agricultural and Resource Economics Society). Disponível em: http:// www.nzier.co.nz. Acesso: 15/dez/02.

CONAB (Companhia Nacional de Abastecimento). Custos de Armazenagem. Brasília: CONAB, 2002. Disponível: http://www.conab.gov.br. Acesso: 06/nov./2002.

FAO (Food Agriculture Organization). FAO’s Database, 2002. Disponível em: http://www.fao.org. Acesso: 21/dez/02.

NAGURNEY, A., NICHOLSON, C.F., BISHOP, P.M. Spatial price equilibrium models with discriminatory ad valorem tariffs: formulation and comparative computation using variational inequalities. In: VAN DEN 
BERGH, J.C.J.M., NIJKAMP, P., RIETVELD, P (eds). Recent Advances in Spatial Equilibrium Modelling: methodology and applications. New York: Springer, 1996.

OMC (World Trade Organization). WTO’s Databases. 2002. Disponível em: http://www.wto.org. Acesso: 11/abr/01.

RUTHEFORD, T.F. Extension of GAMS for complementarity problems arising in applied economic analysis. Journal of Economics Dynamics \& Control. 19, 1995. p. 1299-1324.

SAMUELSON, P. Spatial price equilibrium and linear programming. American Economic Review. 42, p. 283-303. 1952.

SULLIVAN, J. et al. 1989 global database for the Static World Policy Simulation (SWOPSIM) modeling framework. Washington, D.C.: USDA/ERS, Staff Report nº. AGES 9215. 1992.

TAKAYAMA, T. e G. JUDGE. Spatial and temporal price and allocation models. Amsterdam: London: North-Holland Publishing Company, 1971.

THORE, S. Economic logistics: the optmization of spatial and sectoral resource, production and distribution systems. New York: Westport: London: Quorum Books, 1992.

UNCTAD (United Nation Conference on Trade and Development). UNCTAD -Trains (Trade Analysis and Information System), 2001. Disponível em: http://www.unctad.org. Acesso: 15/dez/01.

USDA (United States Departament of Agriculture). Rice Outlook, Washinton: USDA, 2001a. Disponível em: http://www.ers.usda.gov. Acesso: 15/dez/01.

Grain: world market and trade. november, 2001b. Disponí- 
REVISTA DE ECONOMIA E AGRONEGÓCIO, VOL.1, No 3

vel em: http://www.fas.usda.gov. Acesso: 04/mar/2002.

Ocean Rate Bulletin. March 31, 2002. Disponível em: http://www.usda.gov. Acesso: 04/mar/2002. 